\title{
Capability of social life cycle assessment for analyzing the artisanal small-scale gold mining sector-case study in the Amazonian rainforest in Brazil
}

\author{
Sally K. Springer ${ }^{1} \cdot$ Bernhard G. Peregovich $^{2} \cdot$ Mario Schmidt $^{1,3}$ (D) \\ Received: 27 December 2019 / Accepted: 28 September 2020 / Published online: 10 October 2020 \\ (C) The Author(s) 2020
}

\begin{abstract}
Purpose Gold extraction in the Amazonian rainforest is accompanied by ecological threats and social grievances, but at the same time, the artisanal small-scale gold mining sector (ASGM) provides a livelihood for many people. To address this tradeoff, this paper analyzed the social aspects and their possible relations by conducting a case study based on a Social Life Cycle Assessment (SLCA). This study seeks to determine whether SLCA is capable of reflecting the sector.

Method A literature-based guideline was used for collecting primary data during several field trips to the Tapajós Region in Brazil. This research instrument constituted the basis for information-oriented interviews and on-site observations. The SLCA categories used in this study were based on the United Nations Environment Programme and the Society of Environmental Toxicology and Chemistry (UNEP/SETAC) guidelines and the categories in the Fairmined Standard. In addition, secondary data obtained from the literature were used to provide insights into the sector. The data were analyzed using qualitative content analysis with both deductive and inductive approaches.

Results and discussion This study described the social aspects of the ASGM sector in the Tapajós Region, including the absence of the state, the illegality and informality of mining operations, the remote and rural area, and the organizational structure. In addition, the extraction methods, poor working conditions, and difficult living conditions were considered. Certain characteristics of the industry like unstable payments, worker movements, and low education levels were recognized, and thus, the relations among the social categories and rebound effects were identified. Several issues were proven to be key factors: unstable payments, autonomy, and the rebound effects of excavators. Complex relations among social issues but also towards ecological and economic issues do exist. The suitability of using the SLCA to reflect the ASGM sector was tested on this basis.

Conclusion In some respects, the SLCA had limitations, e.g., due to the nonlinear relation between working hours and the amount of extracted gold. The impacts of technology depend on the underlying definition that is used. The current lack of cause-effect models impedes the assessment of an overall picture that considers the relations among the social aspects and other elements of sustainability. A holistic view must be applied if ecological problems are to be solved.
\end{abstract}

Keywords Ecological · Economical $\cdot$ Social and socioeconomic aspects $\cdot$ Sustainability $\cdot$ Resource extraction $\cdot$ Autonomy Excavator

Electronic supplementary material The online version of this article (https://doi.org/10.1007/s11367-020-01828-3) contains supplementary material, which is available to authorized users.

Mario Schmidt

mario.schmidt@hs-pforzheim.de

1 Institute for Industrial Ecology, Pforzheim University, Tiefenbronner Str. 65, 75175 Pforzheim, Germany

2 Federal University of Western Pará (UFOPA), Rua Vera Paz, s/n (Unidade Tapajós) Bairro Salé, Santarem, Pará, Brazil

3 Faculty of Sustainability, Leuphana University Lüneburg, Universitätsallee 1, 21335 Lüneburg, Germany

\section{Introduction}

The importance of the conservation of the Amazonian rainforest is not novel but has recently gained increasing attention because of the ongoing debate about climate change. Due to its large share of rainforest and its political situation, Brazil is in the center of both public and research discussions (de Area Leão Pereira et al. 2019; BBC News 2019; Phillips 2019). While further declarations of natural reserves are debated and new preservation areas are created, the people living in the rainforest and their social structures must not be 
forgotten. The consideration of these important aspects may lead to the limitation of some options that could weaken environmental burdens, and thus, a dilemma has arisen. Several types of activity take place in the rainforest, e.g., logging, farming, and resource extraction (Aide et al. 2013). The extraction of gold by the artisanal small-scale mining (ASM) sector simultaneously serves as a source of income for thousands of people and threatens the ecology (Fritz et al. 2018; Hoadley and Limpitlaw 2004; iied, WBCSD 2002). Deforestation, mercury exposure, and sediment input into rivers have great impacts, such as water ecotoxicity and climate change (Kahhat et al. 2019). These environmental problems must be addressed; however, this cannot be done without paying attention to all three parts of sustainability: the ecology, economy, and society. A holistic view must be adopted when considering the effects of gold extraction.

The "NaGold" project was established in 2015 and has been funded by the German Federal Ministry of Education and Research. Its goal is to assess all aspects of the sustainability of gold extraction and recycling, including ASM, closing the gaps in the life cycle assessment (LCA) methodology and providing suggestions for action. LCA aims at identifying the environmental aspects and potential impacts along the life cycle of a product and is formalized in ISO 14040 (DIN 2009). In addition to ecological threats, the diversity and particularity of social aspects need to be taken into account when considering the overall picture of sustainability (Traverso et al. 2012). The social life cycle assessment (SLCA) methodology addresses these aspects. SCLA follows the same scheme as LCA but aims at estimating the positive and negative social and socioeconomic aspects along the life cycle of a product or service (Benoît and Mazijn 2009). The SLCA method is still in the development stage and has not reached maturity (Teah and Onuki 2017; Petti et al. 2018). Questions have been raised such as: What exactly does the method reveal? In addition, questions regarding its application have been raised (Clift 2016). Some even state that it is impossible to carry out a full SLCA and that researchers should put effort into further development of the theory (Macombe et al. 2013).

The aim of this paper is to analyze the social aspects of the artisanal small-scale gold mining sector (ASGM) sector and their relations by conducting a case study based on content from an SLCA to determine whether SLCA is capable of reflecting the ASGM sector.

One article in the preproceedings of last year's SLCA conference discusses the identification and development of a framework that can address the social aspects of ASM and debates, if "social issues associated with ASMs can be analyzed from a life cycle perspective", but without providing an answer yet (Zerazion et al. 2018).

The largest ASM population in South America is estimated to be in Brazil (Seccatore et al. 2014). The Tapajós Region of the Brazilian rainforest is one of the world's largest areas with ASM sites (da Silva 2001; Sousa and Veiga 2009). Many informal mines are located in this region (Looted Amazon 2018). For these reasons, the Tapajós Region in Brazil was chosen as the research area. Reliable data and statistical information on the informal and illegal sector is lacking. Therefore, a local survey is necessary. Only in this way can the ecological, economic, and social aspects of ASM be assessed. Several field trips in cooperation with the Federal University of Pará in Santarém (Brazil) were included as part of the project.

In Brazil, the term Garimpagem is used as a synonym for ASM. According to Brazilian law, Garimpagem refers to the rudimentary work in which individuals extract gemstones and minerals from deposits (Presidência da República, Casa Civil 1967). The mine where the deposit extraction takes place is called the Garimpo. A Garimpeiro or gold miner is any person who is involved in the extraction process (Presidência da República, Casa Civil 2008, Art. 2 I + II). The owners of Garimpos are called Donos. ASM is defined differently in several countries; thus, there is no worldwide consensus on its definition (Hentschel et al. 2003). In this paper, the abbreviation ASGM is used to refer to artisanal small-scale gold mining and exclude resources other than gold.

Since 2010 , the share of gold originating from Garimpagem has varied between 10 and $25 \%$ of total gold production in Brazil with a peak of $23.625 \mathrm{t}$ in 2016 according to the National Gold Association ANORO (2019). This reveals the potential of ASGM, even though these estimates do not match the actual figures. The Agency for Technological Development of the Brazilian Mineral Industry (ADIMB, 2019) estimates the amount of illegal mined gold to be $30 \mathrm{t}$ per year.

Several specific characteristics of the ASGM sector have been described in the literature, and we have also encountered them in our research. ASM can be formal, informal, legal, or illegal, where illegal means that no claim has been proposed or approved (Veiga 2013). The sector is driven by poverty and is a source of income for many people (Hentschel et al. 2003). Quick income, possible wealth, and low or even no educational requirements are further drivers to enter the sector. Moreover, many people living in the considered region are illiterate (Sousa and Veiga 2009). As a result, alternative income opportunities are limited because education is often needed for employment in formal sectors (Kolen et al. 2017). Migration takes place to and between mining sites in rural areas (Sousa and Veiga 2009). Due to the remoteness of these areas, there is a lack of access to several institutions, e.g., health facilities or financial institutions (Hentschel et al. 2003; Hinton et al. 2003a). Schools appear to be increasingly established but only in their rudimentary forms. Employment contracts do not exist; everyone is free to leave when they so desire (Cleary 1990). Payment is split between a 
group of people and equals a specific percentage of the value of the extracted gold (Kolen et al. 2013). Technological changes sometimes lead to changes in working conditions (Massaro and de Theije 2018) and are visible in the usage of retorts and excavators. Overall, the workers' health can be negatively affected by disease and dangerous occupational threats, e.g., mercury exposure (Hinton et al. 2003a; Priester and Hentschel 1992; Veiga 2013; Wotruba et al. 1998). There is a strong shared identity among gold miners (Kolen et al. 2017), and due to the absence of the state, the rules they have established have strengthened over time (Geenan 2016; Kolen et al. 2013). Therefore, Garimpeiros operate in a more autonomous and self-determined way (Mathis 2012). "Autonomy" in this context can also be understood as lawlessness. However, from the point of view of the Garimpeiros, it is seen as something positive, as their illegal activities are not prosecuted. Although their characteristics and problems are well known, information on their relations is lacking.

The clustering of social aspects is beneficial for obtaining a clear overview of the complex situation. Several institutions and management standards include such clusters, e.g., ISO 26000 (DIN 2011), SA8000 (Social Accountability International 2014), and the Global Reporting Initiative GRI (2016). Also, the SLCA methodology considers predefined social aspects. Among these standards, there is no consistency in the terminology that is used. The Roundtable for Product Social Metrics (RPSM) (Goedkoop et al. 2018) proposed the Product Social Impact Assessment method and has provided a list of several social topics that can be assessed. A social topic in the RPSM is called a social theme in the Social Hotspot Database (SHDB) (Benoit-Norris et al. 2012) and a subcategory in the Product Social Impact Life Cycle Assessment (PSILCA) database (Eisfeldt and Ciroth 2017). The Guidelines for Social Life Cycle Assessment of Products published by the United Nations Environment Programme and the Society of Environmental Toxicology and Chemistry (UNEP/SETAC) (Benoît and Mazijn 2009) (UNEP/SETAC guidelines in the following) also use the term subcategories. For simplicity, the term category is used in this paper. In the UNEP/SETAC guidelines, 22 categories for the stakeholders of workers, consumers, the local community, society, and value chain actors are listed. These categories were created based on international agreements, conventions, and frameworks (Benoît and Mazijn 2009) and are used for this case study because it is an important publication in the SLCA field (Corona et al. 2017; Kühnen and Hahn 2017). The definitions of these categories and their relevance for sustainable development can be found in the Methodological Sheets, an accompanying document of the UNEP/SETAC guidelines, and are helpful for matching a specific social aspect to a particular category (Benoit Norris et al. 2013). Another reason for choosing these social categories is the underlying life cycle perspective of the method, as one goal of the NaGold project is to improve LCA.

\section{Materials and methods}

\subsection{Social life cycle assessment}

SLCA estimates the social and socioeconomic aspects along the life cycle of a product or service, and both positive and negative impacts are assessed (Benoît and Mazijn 2009). Social aspects are identified and evaluated to allow products/ services to be compared and to trigger dialog and discussions (Corona et al. 2017). SLCA can also be used for research purposes, socio design, or supply chain optimization (Zamagni 2018).

A standardized approach for SLCA has not existed until now (Iofrida 2016; Siebert et al. 2016), and methodological approaches and applications are still in the development phase (Muthu 2015), because in contrast to the research field of LCA, the research field of SLCA is in the development stage (Martínez-Blanco et al. 2014; Spierling et al. 2018). A major challenge lies in the availability and access of regional-, sectoral- and site-specific data (Jørgensen 2013; Macombe et al. 2013). This is also the case for mining (Neugebauer et al. 2018). A study found that for mining on a larger scale (excluding ASM), the SLCA databases (SHDB and PSILCA) have limitations in terms of portraying the social aspects of a sector (Mancini and Sala 2018).

The methodology proposed in the UNEP/SETAC guidelines (Benoît and Mazijn 2009) includes certain steps: goal and scope (G\&S), life cycle inventory (LCI), life cycle impact assessment (LCIA), and interpretation. The first phase involves identifying the purpose of the study and its boundaries, e.g., attributional or consequential modeling. Data collection, system modeling, and choosing inventory indicators and also relating them to the functional unit take place during the LCI phase. Data collection can be prioritized by choosing an activity variable $(\mathrm{AV})$, e.g., value added, which measures the output of a process and thus can "reflect the share of a given activity associated with each unit process" (Benoit and Mazijn 2009). Working hours can be considered the most commonly used AV for scoring and is used by UNEP/SETAC and PSILCA among others (Eisfeldt and Ciroth 2017; MartínezBlanco et al. 2014). Furthermore, the results of the LCI are generated. During the LCIA, the impact categories and subcategories are selected, and the characterization methods and models are chosen. The classification and characterization processes also take place. For the characterization process, several options exist - type I (aggregating the results at impact categories level within one topic of interest), type II (social impact pathways), or life cycle attribute assessment (coverage of supply chains by considering certain attributes). The last phase consists of interpreting the results and presenting the conclusions.

In terms of the capability of the SLCA method for a specific sector, the aspects of all phases are crucial. As the 
relations of a sector should be considered, the system boundaries are of interest. Whereas consequential LCA assesses the effects of changes or decisions regarding unit processes (Weidema and Ekvall 2009), consequential SLCA compares an implemented life cycle to a non-implemented life cycle (Jørgensen et al. 2010). The UNEP/SETAC guidelines indicate that the development of consequential SLCA is necessary and will likely continue in the future (Benoit and Mazijn 2009). According to Clift (2016), the development of consequential SLCA is unlikely unless the attributional approach currently in use reaches a stable level of development. Characterization within LCIA is crucial when discussing relations. While type I uses performance reference points by consulting additional information, type II LCIA reflects causaleffect chains (Parent et al. 2010). There is a lack of consistent relationships (Jørgensen et al. 2008).

\subsection{Research strategy}

A qualitative research strategy was followed. In order to close the lack of data about social structures in the Brazilian ASGM sector, many different sources of data were gathered together using a case study. The lack of data is also the reason for conducting an exploratory research design with the objective for generating an understanding of the sector.

\subsection{Data collection}

Different research methods came into place to collect data. Secondary data were obtained from the literature with text analysis, e.g., Buxton 2013; Kolen et al. 2013; Kolen et al. 2017; Mathis 2003; Sousa and Veiga 2009. Primary data were gathered through ethnography research. Several field trips took place in the period of 2017-2019 to gather as much data as possible mainly via information-oriented interviews with complementary observations (see Yanow et al. 2013). The research area was the Tapajós Region, which is located in the northern state of Pará in Brazil. Visits were made to small municipalities in rural areas as well as Santarém and Itaituba and approximately 30 mining sites. Ethnography research was conducted by employing a survey instrument that followed a literature-based guideline. This instrument consists of sample questions related to stakeholders and social aspects and builds the basis for interviews and observations.

Garimpeiros and Donos are fundamental actors in the sector, and thus, the sample questions were formulated to mainly target these stakeholder groups. In addition, politicians, scientists, shop owners, nurses, teachers, and many more were interviewed. First contacts with interviewees emerged from the existing connections of one member of the research team, and the interviews were partly arranged in advance. In addition, snowball sampling was used to create an understanding of the network (see Bryman and Bell 2011).
Social aspects, e.g., the health of workers, were identified in the literature and attached to predefined categories of SLCA, e.g., the health and safety of workers, by using the UNEP/SETAC guidelines for workers, the local community, and society (Benoît and Mazijn 2009). Therefore, SLCA categories form the basis of the investigation. In addition, the Fairmined Standard proposed by the Alliance for Responsible Mining (ARM 2019) was reviewed, and categories added where no coverage was already given by UNEP/SETAC. Due to this adjustment, sector-specific categories were included. This deductive, explorative approach was followed to minimize the risk of ignoring important aspects. New categories were inductively defined for all other social aspects identified in the literature where no suitable category was available (e.g., education and transportation infrastructure). Sample questions (e.g., How many hours per day do you work?) were developed. Because this research is exploratory, partly open and partly closed, structured information-oriented questions were used to generate as much information as possible.

The guidelines that were developed based on the literature can be found in the Online Resource Table 1. This instrument was constructed to be flexible in terms of order and formulation to increase validity. The categories and sample questions were modified and extended to adapt to specific situations that occurred during the field trips and to be able to take up on answers. Using this inductive approach, new findings were steadily included. This further development of the literaturebased guideline resulted in the creation of new categories during field trips (e.g., autonomy and social insurance). The new categories and sample questions can be found in Table 2 of the Online Resource.

In total, 67 interviews with individuals between the ages of 16 and 70 were conducted. Seven interviewees were female. Most interviews were conducted with Donos and Garimpeiros (46\%). The other interviewees were representatives of Association for Garimpeiros (6), entrepreneurs (4), professors and students (4), representatives from state institutions (3), consultants (3), geologists (2), pilots (2), nurses (2), a teacher (1), and a mayor (1). The questions were asked by a multidisciplinary team of economists, environmental scientists, and geologists and were mainly asked in Portuguese and English. If the interviewees gave their consent, the conversations were audio-recorded, and notes were taken. The duration of the interviews varied from a few minutes to more than $2 \mathrm{~h}$. By asking the same questions to different people and at varying locations, the methodology of triangulation was followed to verify results.

\subsection{Analysis of data}

The data were evaluated using qualitative content analysis, following the approach of Mayring, which is described in 
detail in Mayring (2014). This research method is also used in other contexts, e.g., Hospido et al. (2009), Cobut et al. (2013), or Du et al. (2019). The collected data consisted of handwritten notes from the field trips, audio recordings of interviews, and summaries of the audio recordings. The recordings were documented word for word in written form. The information included in these materials was considered to reflect the actual state of the sector and was systematically evaluated. A deductive approach was followed by attaching keywords (e.g., hope, working hours, and mercury) to the data, keeping in mind the predefined categories in the literature-based guideline (see Section 2.2.). At the same time, we followed an inductive approach and were open to adding new keywords that emerged during the analysis. In the second step, these keywords were grouped into social states using the interviewees' own wording. Based on the findings, the relations of the social states with the categories were identified. Again, using an inductive approach, the need for additional categories became apparent, and two new categories (environment and productivity) were added. In this context, productivity means that more output can be produced in the same time. Then, the connectivity of social aspects with the ecological and economic aspects became clear. The results should always be viewed critically and questioned. The transparent disclosure of the research approach gives everyone the opportunity to evaluate the results.

\section{Results and discussion}

\subsection{Case study-qualitative descriptions of the social states and their relations}

Based on the findings of prior studies and the evaluation of the primary data, the social states regarding Garimpeiros that are typical of the ASGM sector in the Tapajós Region were identified. In the following, these social states are defined and their complex relations with social categories are outlined, with the aim of better understanding the interwoven effects of the sector. The descriptions of the results are provided in Fig. 2 as an overview. The legend is provided in Fig. 1. The sectors are expressed in hexagons. The ASGM-specific social states are expressed in quadrangles with square edges (e.g., unstable payments). An arrow indicates a relation, which means that the starting point has an influence on the endpoint. The social categories are expressed in square boxes with rounded edges (e.g., fair salary). Further relations between the social categories are regarded as secondary and are expressed in arrows with dotted lines; these sometimes lead to rebound effects. The driving forces and outcomes are expressed in thick arrow-shaped boxes (e.g., livelihood). Relations exist more or less between all social states and categories. The selected relations and resulting rebound effects, which are particularly striking from our point of view, are described more precisely after the limitations are discussed. The results are based on the data collected during the field trips as well as the literature. Due to the methods used during the field trips, the data could be biased. The number of interviews and interviewees is adequate for generating an understanding of the sector; however, they might not be representative. Another limitation might be that the detection of existing relations is complex and can vary in a given time frame. Not all of the relations could be revealed or described in this study. Notably, the identified social states of the sector are interrelated and leave room for more precise research, which has been neglected here due to the level of complexity. We suggest that further research should be conducted to reveal more relations as well as their meanings from an anthropological and sustainability point of view to outline action and measures that can be taken to address the dilemma of attributing the same attention to the ecological, economic, and social aspects of sustainability.

Poverty and wealth The motivation to become a Garimpeiro can be encouraged by poverty and by the chance of becoming wealthy. According to the literature as well as our own findings, Garimpeiros dream about becoming wealthy from 1 day to another through Bamburro: finding a large amount of gold (Geenan 2016; Heck and Tranca 2014; Larreta 2002).

No presence of the state Government structures cannot be found in the Brazilian rainforest. Laws and rules are not present, and there are no institutions (e.g., public offices) in the region. Police stations are very rare. Controls to detect illegal mines are occasional. The head of the former Departamento Nacional de Produção Mineral (DNPM), now known as the ANM, explained that controls should take place more often, but this does not occur because of the lack of financial resources. Furthermore, corruption is common in Brazil (Transparency International 2019). As part of our surveys, the topic of corruption was not explicitly investigated. But many interviewees stated corruption as a big problem; e.g., the aim of a control seems to not be combating illegal mines but rather to make money by receiving bribes. Over time, the local community and Garimpeiros have developed their own rules. This phenomenon was also observed in Africa by Geenan (2016). In different Garimpos, people explained to us that if someone steels gold or personal belonging from colleagues, the person will be shot dead. It was also narrated that there has been a high level of criminality in the past, but that it became less since everyone is familiar with the rules. However, there is little awareness that this form of punishment is also criminal.

On the one hand, this hampers legality and formalization. On the other hand, the non-presence of the state allows the Garimpeiros to enjoy autonomy, which are their most valuable intangible "assets." This aspect was not considered in the 


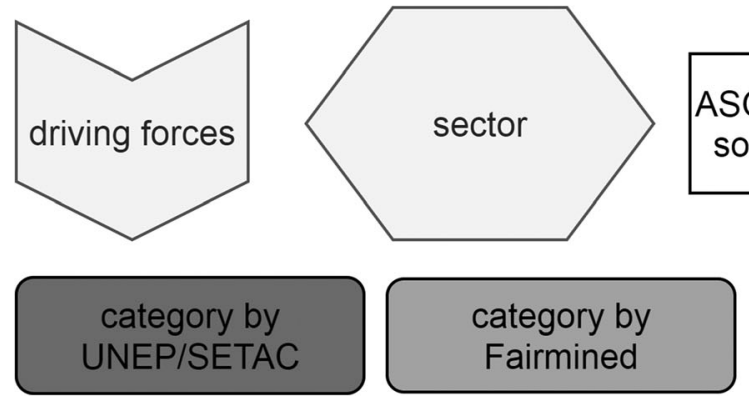

ASGM typical social state

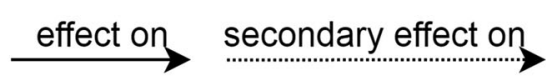

category developed by authors

outcome

Fig. 1 Legend of Fig. 2

past, and no category for this aspect exists in the UNEP/ SETAC guidelines or Fairmined Standard, but the topic has great meaning for understanding the social situation in the sector. Therefore, a new category "autonomy" was created. A possible consequence of this aspect could be the rejection of alternative formal income options (see section "Alternative income opportunities in other sectors").

Illegal and informal There is no predefined category for this aspect in the UNEP/SETAC guidelines or Fairmined Standard, but as the high level of illegality and informality reflects a major social state of the ASGM sector in Brazil, a new category was created. All interviewees shared the same information: it is estimated that approximately $10 \%$ of ASGM in the Tapajós Region is legal. Verifiable data are not available, which makes it difficult to review this appraisal. The illegal actions result in tax losses for the state. To operate a mine legally, a claim has to be made to ANM. These offices can be thousands of kilometers away from the mining areas. Claiming of mining rights includes a description of the mining site with an expert report (e.g., of a geologist) and an environmental license (DNPM, (o.J.); Presidência da República, Casa Civil 1989). Illiteracy and low education levels tremendously hamper this process. There is a high level of bureaucracy, and the fee for mining is expensive. These fees have been identified as obstacles by other researchers (Kolen et al. 2013). There are no direct governmental institutions that support the formalization process. The SIGMINE map of DNPM is supposed to provide an overview of different areas in the rainforest, e.g., for which areas a mining concession has been claimed, pending areas or restricted areas, but is not up to date (DNPM 2019). In 2019, Jair Bolsonaro became state president

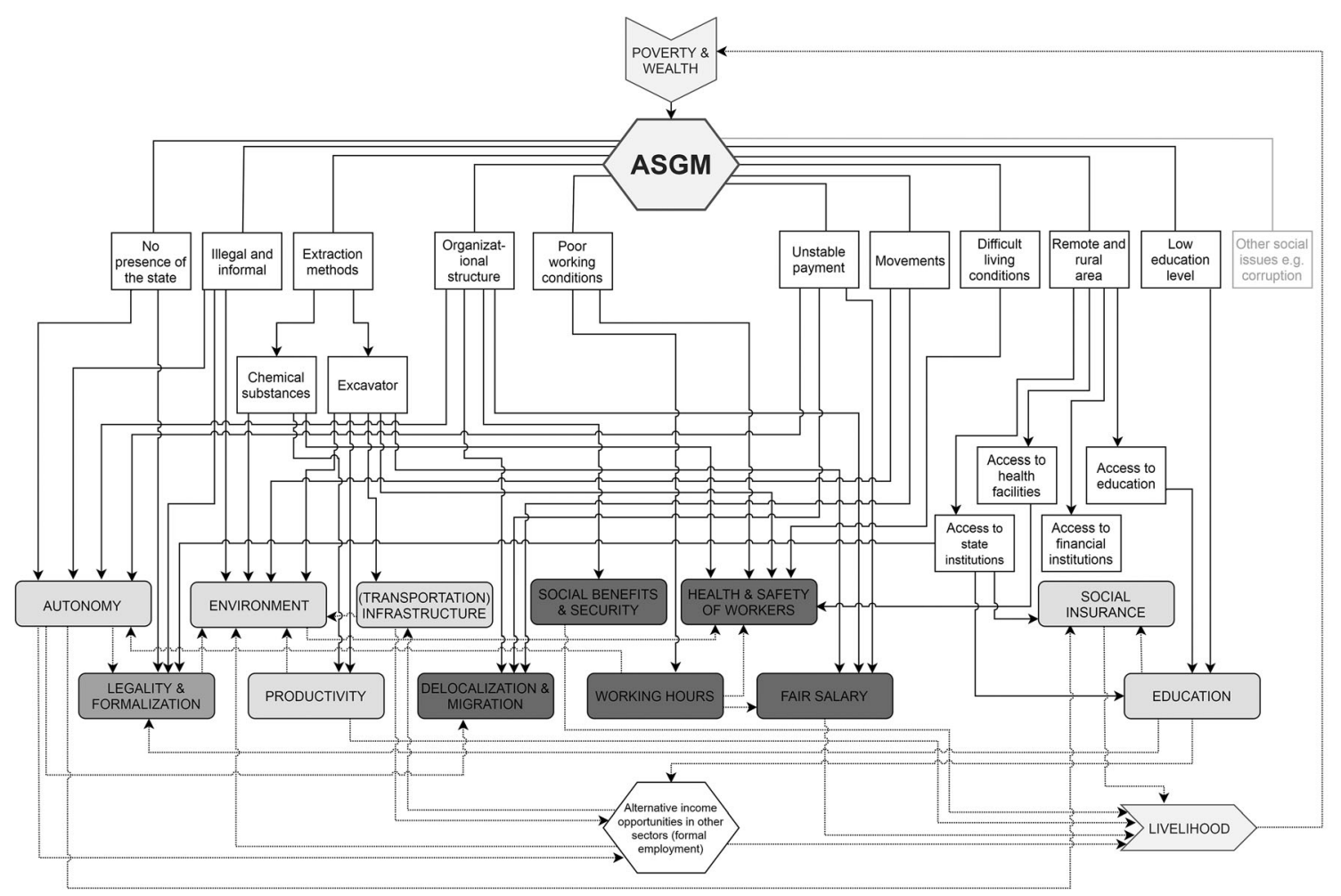

Fig. 2 Social states, categories, and their relations. Relations between the social states and categories; the categories were derived from Benoit and Mazijn (2009), ARM (2019), or developed by the authors. Note that not all relations are depicted in this work and figure 
of Brazil. Since then, the political situation about formalization and mining rights changed fundamentally. For example, due to the withdrawal of the task of issuing environmental licenses by the environmental authority (Maisonnave 2018). For Donos, becoming legal means that they face a lower risk of penalties but must exert more and face higher costs. Furthermore, being part of legal and formalized structures can be seen as an obstacle, as it could mean the end of autonomy. A possible consequence of not following the law is that there will be less or no environmental protection. Therefore, a new category "environment" was created.

Extraction methods In the Tapajós Region, three extraction methods are used: the underground mining of primary rocks, mining of secondary deposits with sluice boxes (Caixa), and mining of secondary deposits with so-called Dragas or Balsas directly in the riverbeds. In all extraction cases, mercury is used to recover the gold. The tailings contain gold and can be further processed with cyanide in a vat leaching process (see also Sousa and Veiga 2007). The mining of secondary deposits is achieved by deforestation followed by the removal of the topsoil; this can be done with or without excavators. Excavators are also likely to be used in underground mining. For more information about extraction methods, see Priester and Hentschel (1992) or Veiga et al. (2006). More information about environmental impacts including the mercury footprint and $\mathrm{CO}_{2}$ emissions can be found in Valdivia and Ugaya (2011).

Chemical substances Mercury and cyanide affect the environment as well as human health and safety (Hentschel et al. 2003; Sousa and Veiga 2009; Veiga et al. 2006; Wotruba et al. 1998). Due to the accumulation of mercury and cyanide in the environment, the health of workers and the local community is further threatened (Veiga et al. 2006). However, productivity (category established by the authors) increases when mercury and cyanide are used; therefore, they have a rebound effect on health and safety, the environment, and people's livelihood. We found that the use of a combination of these chemicals is becoming increasingly popular. Through amalgamation, gold can be extracted directly at the mining site, while cyanidation takes up to 3 weeks, as the latter is mostly executed by a third-party service provider.

Excavators According to our findings, excavators have been increasingly deployed since around 2010 (Schmidt and Peregovich 2015). Now, excavators are almost standard for Garimpos in the Tapajós Region. Productivity increases with the help of excavators; they approximately quadruple the amount of gold that can be extracted compared with that from manual work as they increase the mining speed. Salary increases accordingly and has a positive influence on livelihood. Since the introduction of excavators, work has become easier and safer in some sense, influencing the health and safety of the workers. Heavy machinery and materials do not have to be carried on the backs of the Garimpeiros, as the excavators can now transport them. Furthermore, work is safer in some respects, as dangerous chainsaws are not used to cut down the forest, and the excavators provide protection from falling trees. Notably, there is a new source of risk that is commonly associated with handling heavy machinery. With an excavator, it is economically viable to reopen old mines because a secondary forest is not so deeply rooted, and it can be easily cleared. Furthermore, mining pits can be dug almost anywhere when an excavator is used, regardless of the composition of the surface. This increased availability affects the environment, as more deforestation takes place, more terrestrial ground is processed, requiring more water from rivers and operating materials, e.g., fuel and mercury. Since more ground is processed, there are more tailings, and there is more sediment input with residues of chemicals that flow into the rivers. However, excavators can reduce sediment input. The material above the gold-bearing layers can be dug out in a dry manner instead of using water pumps to generate sludge. The processed pits can be filled with dry topsoil and accelerate the recovery of flora. In addition, with the help of excavators, roads can be built, leading to additional (transportation) infrastructure, which was added as a new category. The increase in the number of roads has a secondary effect. As access to mining sites becomes easier, settlements are more likely to form. This easier access attracts not only more Garimpeiros but also workers from other sectors, e.g., loggers or cattle breeders, who see an opportunity to start a business in the rainforest, which in turn affects the environment.

Organizational structure Anyone can become a Dono if they have enough capital at their disposal. The Dono organizes the equipment, e.g., pumps and excavators, and opens a camp. Donos and Garimpeiros can differ in terms of their literacy, knowhow, or experience, but the feeling that everyone is equal is more dominant. As one Dono said in an interview, "People like to work as Garimpeiros because everyone is the same. They do not feel inferior but rather accepted by everyone." Garimpeiros see themselves as entrepreneurs and partners of the Donos, working with them rather than working for them. Written contracts usually do not exist. If the Garimpeiros want to work somewhere else, they are free to leave. This flexibility can lead to frequent delocalization and migration. These informal agreements could be interpreted as the opposite of forced work, as they allow the Garimpeiros to be flexible, leading to a feeling of autonomy. On the other hand, informal agreements pose risks because the Garimpeiros can decide to leave spontaneously, and the Dono can dismiss workers in the short term, meaning they will have no income any longer (salary according to the UNEP/SETAC guidelines). This informal and thus 
nonbinding characteristic also affects social benefits and security. The interviews revealed that these payments are unstable. If a Garimpeiro becomes sick or cannot work after an accident, sometimes the payments may continue for a few days but not always. In some cases, colleagues decide whether the disabled person will receive some of the payment, as they share the wage and workload (see section Unstable payment). Usually, the Garimpeiro will still be provided with food and accommodation, which constitutes a form of employment compensation. Sometimes, the Dono pays for transportation to health facilities or medication, and sometimes, the Garimpeiro has to pay for these services. Therefore, the influence on livelihood can be positive or negative.

Poor working conditions The working conditions are strenuous and exhausting and affect the health and safety of the workers (Priester and Hentschel 1992; Wotruba et al. 1998). Additionally, the working hours are long and can influence the health of the workers. Some Donos let the Garimpeiros decide how many days per week they work, which is again an example of autonomy. It is hoped that the increase in working hours will lead to an increase in the amount of gold found and thus to an increase in salary. The entire group makes the decision regarding how many days to work because the payment is divided among the group members (see section "Unstable payment").

Unstable payment Garimpeiros are paid in gold not in Brazilian currency BRL. The payment (salary according to the UNEP/SETAC guidelines) is usually not constant but rather a previously defined percentage of the extracted amount of gold. According to our findings, this percentage is usually 15 $17 \%$ of the extracted gold, and it is shared among a group of workers consisting of approximately 5 people. For the Garimpeiro, this aspect is attached to a high level of risk. If a large amount of gold is found, the Garimpeiros can indeed become wealthy from 1 day to the next, but the earnings can also be as little as nothing. Delocalization and migration to other mining sites occur if the Garimpeiros become dissatisfied with the amount of gold found, the Dono or a colleague. This aspect was also mentioned in the findings of the Global Mercury Project (Sousa and Veiga 2009). The minimum monthly salary in Brazil was 963 BRL (218.20 €) on average between 2017 and 2019 (WSI 2019). The monthly income of a Garimpeiro can be several times higher, but also lower. According to our findings, the arithmetic mean of the payment was $2.850 \mathrm{BRL}$ (approximately $660 € /$ month) when using excavators, taken into consideration that only in approximately 10.5-11.5 months gold extraction takes place due to the wet season. It is important to exercise caution with these numbers. Payment data of our survey ranges between 207 BRL and 13.356 BRL per month, depending on the Garimpo and its gold contents.
Movements As noted by Sousa and Veiga (2009) and based on our findings, a great deal of movement takes place in the mining areas in the rainforest, leading to delocalization and migration. Many Garimpeiros cited income opportunity as a reason for becoming a Garimpeiro, even if they had families in other regions or countries. We observed that the mining pits and connected small camps can be temporary; this has also been reported in the literature (Kolen et al. 2017). If the amount of easily extractable gold decreases, the Garimpeiros will move to other areas, which leads to increased environmental impacts due to the increase in processed ground (see section "Excavator"). Workers decide whether to migrate with the mine or not. Those who stay are left with a lack of economic alternatives (Veiga 2013). However, this is currently changing because more settlements are being developed (Kolen et al. 2017).

Difficult living conditions A Garimpo consists of the actual gold mine and a camp, where the Garimpeiros can live and eat free of charge. It is a simple facility with a large open tent with hammocks that provides shelter and houses a kitchen. Sanitary facilities usually consist of a hole in the ground and a barrel that catches rainwater. Nearby rivers are also used for daily hygiene. A common health problem is parasitosis due to poor water quality. Diseases transmitted by insects, e.g., malaria or yellow fever, are also threatening.

Remote and rural area Garimpos are located in remote rural areas in the rainforest that are sometimes accessible only by boat, small aircraft, and occasionally car. This hampers access to several institutions. The lack of access to state institutions results in multiple problems, one of which is related to the Cadastro da Pessoa Física (CPF), the tax identification number. The $\mathrm{CPF}$ is required for every bureaucratic activity, e.g., making a claim to engage in legal mining activity, providing proof of education, and applying for government social insurance, such as retirement payments (Presidência da República, Casa Civil 1967). However, not everyone is registered and has a CPF. Many Garimpeiros do not want to apply for social insurance from the government because it would contradict their independence from the state. The absence of social insurance payments can be detrimental to a secure livelihood. Due to the importance of this aspect, a new category for social insurance was created. For the gold miners and attached communities (e.g., their children), access to education is considered very important but limited. Very few villages have a primary school, although the presence of such schools seems to be increasing; this has also been observed by other researchers (Kolen et al. 2017). Schools are poorly equipped due to a lack of teachers and educational material. This would be even worse if some communities would not finance the schools by their own. By this, at least a small contribution to education is made and a positive outcome created. After 
primary education, children have to move to larger cities if they want to continue their education, but many families cannot afford such education. All these aspects influence education (category established by the authors). Medical treatment is free of charge in Brazil (Ministério da Saúde 2017b), but there is limited access to health facilities. Additionally, some medicines, e.g., those used to treat malaria, are complimentary (Ministério da Saúde 2017a). Nevertheless, often, the health of the Garimpeiros does not benefit from these policies, as health facilities are too far away. Some villages have a health station, but as we found, this is more the exception than the general rule. There is no access to financial institutions in the form of bank branches; therefore, many people do not have a bank account. In addition, it is not possible to obtain a loan for larger investments from a bank.

Low education level For people with a low education, it might be easier to find an income option in informal structures. Legal mine operators, lawyers, and university professors stated in the interviews that there are almost no other job opportunities for Garimpeiros due to their lack of education. The extant literature and our observations indicate that a large portion of Garimpeiros, mainly those who are older, never had the opportunity to attend school (Hentschel et al. 2003) and are illiterate (Sousa and Veiga 2009). Two major problems result from this lack of education. The first problem is that it impedes all governance-related offers, e.g., the application for social insurance and the ability to legalize mining operations, and thus hampers legality and formalization. The second problem is the lack of alternative income opportunities (see the corresponding section).

Other social issues More social aspects exist than those described in this study, and some of them are listed in the literature-based guidelines developed in this study (Online Resource Tables 1 and 2). Some categories are neglected, as no or few features were observed, and thus, no new information was obtained. For example, no observations were made with children working in Garimpos, which is in line with findings from Villas-Bôas (2003) and from Sousa and Veiga (2009). No prominent findings were made in terms of gender discrimination and equal opportunities. We did meet only a single Garimpeira. Interviewees said that only men work in the mines. On the other side, cooks in Garimpos were always female. This was again also observed by the previously mentioned findings (Sousa and Veiga 2009; Villas-Bôas 2003). Hinton et al. (2003b) write the same about women having rather ancillary roles but also work as Garimpeiros in very small operations. In the past, human trafficking for prostitution of women, also children, took place (Dimenstein 1993; Hinton et al. 2003a), but it was not possible to find out if this is still a threat, although prostitution is very common in the region.
Alternative income opportunities in other sectors (formal employment) Many Garimpeiros do not have other income opportunities, especially in formal sectors, due to their educational background. At present, new jobs as loggers or farmers have evolved due to the improved infrastructure and newly developing settlements and provide people with a livelihood in the rainforest. The creation of alternative income opportunities increases the environmental burden and (transportation) infrastructure. This indirectly influences the environment again. The unwillingness of Garimpeiros to work in formal structures is more crucial. Once they start as Garimpeiros, they never stop. Two Garimpeiros stated that they had other jobs, e.g., as distributors or farmers, in between mining, but they always returned to the mines. One interviewee made a powerful statement about this aspect: "It is easy to make a Garimpeiro out of a man but not to make a man out of a Garimpeiro." What he tried to say is that most Garimpeiros cannot get away from this business once they start. Even though they were able to secure permanent employment with secured income, some people decided to return to this informal business. An interview with the owner of a large industrial mine revealed that it is difficult to find employees, as people prefer to work in Garimpos and bear the risks rather than having prescribed working structures and risk-free income. One reason for this might be that once a person has experienced the free and open structures of Garimpagem, it is difficult to go back to following rules. The excitement surrounding gold and the subsequent possibility of becoming wealthy affect these decisions because they perceive it as autonomy. This is one of the major findings of this study.

Livelihood The ASGM sector provides many people with a livelihood. Veiga (2013) cites the UN and states that every Garimpeiro generates an economic benefit for ten other people, e.g., family members, fuel suppliers, or jewelry manufacturers. Buxton (2013) estimates that the number of people that receive an indirect benefit is 3-5 times higher than the number of ASGM miners. According to Hilson (2002), 10,000 mines have approximately $1,000,000$ employees. In 2014, the estimated number of people involved in ASGM in the Tapajós Region was 35,000 (without indication of legal status) (Heck and Tranca 2014). The derivation of our own estimates lies in the same magnitude and is as follows: to our knowledge, since 2010, there was one trader who offered to finance excavators. He sold approximately 1800 excavators to the region and contributed greatly to their usage. This trader is considered the largest seller in the region and also provides maintenance and training for operators. He estimates that approximately $60 \%$ of these excavators are still in use, i.e., 1100 operating excavators. It is assumed that for each Garimpo, there is one excavator and approximately $2-3$ open pits. Approximately 5 people work in each pit. According to this, approximately 14,000 people are directly involved in mining 
of secondary deposits in the Tapajós Region. The actual number is likely to be higher for several reasons. Fluvial mining of secondary deposits and underground mining are not included. It is suggested that approximately $20 \%$ of the gold originate from these sources, resulting in a number of approximately 17,000 people. It is likely that there are other excavator dealers in this region. The estimated number of excavators is subject to fluctuations as people come and go depending on the gold price and amount of gold found.

The purchasing power generated by this sector can be used to reduce poverty of the Garimpeiros but also for the local community (Owusu et al. 2019). There is always a chance of gaining wealth by finding a large amount of gold. One would think that as soon a person has enough money set aside, the rainforest as a home would be exchanged for living in a formalized city with urban infrastructure. However, we found the opposite: wealthy Donos stayed in the rainforest and said that it is where they belong. There is a strong sense of identification, as the Garimpagem is not seen as a temporary solution but rather as a profession with passion. In addition, small villages only exist because of gold miners as this poses a chance of earning money, e.g., as shop or bar owner, prostitutes, or mechanics.

\subsection{Capability of SLCA to reflect the ASGM sector}

The capability of SLCA can be investigated by considering the case study results described in Section 3.1 and illustrated in Fig. 2. In general, the SLCA methodology has room for improvement, e.g., due to the lack of a standardized method, the handling of the functional units, and the indicator selection process (Iofrida 2016; Siebert et al. 2016). In recent years, many case studies have been executed to test and further develop the method (Du et al. 2019; Teah and Onuki 2017; Zamani 2016). In the present paper, the key issues of the ASGM sector in Brazil are derived and tested according to the capability of the SLCA methodology.

\subsubsection{Key issue 1 - unstable payment}

Because the payments to the Garimpeiros are related to the amount of gold they find, which fluctuate, the payments are unstable. In the ASGM sector in Brazil, one major aspect is the nonlinear relation between the working hours and amount of extracted gold. The relation between the working hours and amount of extracted gold and that between working hours and value added could be used as AVs in SLCA (see Section 2.1). The nonlinearity of the relations could be an obstacle for conducting an SLCA because the relative importance of a process cannot be identified due to the large fluctuations in the number of working hours and amount of extracted gold and thus value added.

\subsubsection{Key issue 2-autonomy}

As we have observed in numerous interviews, "Autonomy" represents the most important intangible "asset" of the Garimpeiros and is a significant aspect of the ASGM sector in Brazil. The Garimpeiros themselves speak of "Freedom." As there is no predefined category in either the UNEP/SETAC guidelines or the Fairmined Standard, we originally started from the term "Freedom and Autonomy" as a new category. It reflects the Garimpeiros understanding of alleged autonomy and independence, in the sense of making their own decisions excluding any interference from others.

But we have to be careful: What we describe is not exactly the same as the human right of freedom as Garimpeiros are not unfree. In the cases we have studied, there is no slavery. The following definition should clarify this: Berlin (1969) distinguishes between negative and positive freedom, using the two terms freedom and liberty synonymously. Normally, being free means that nobody interferes with my activity. Freedom in this sense means simply that a person can act unobstructed by others. But that is the "negative" freedom. Positive freedom is the ability of self-determination (Berlin 1969). Carter makes this clearer: negative liberty means "the absence of obstacles, barriers or constraints" in a way that no one is stopping you from actions you want to do. Positive liberty means you are able to act autonomous in your own interest (Carter 2016).

Our observations revealed the importance of this aspect, and they are described in the results (Section 3.1, sections: No presence of the state, illegal and informal, organizational structure, poor working conditions, and unstable payment). Since the state is not present, there is no noticeable state interference or legal prosecution, which leads to a certain "negative" freedom for the Garimpeiros. They have the feeling of not being responsible to others, which is reinforced by the fact that there are hardly any other people in the remote areas. The gold mining communities have established their own rules. In the rainforest, sanctions for disregarding the rules can be strong and even lead to death. Nevertheless, Garimpeiros see advantages in this - punishment is fast and bureaucratic processes can be avoided. No one else interferes. It creates the impression of being free and autonomous. Working with Donos as an alleged equal partner and without working contracts further conveys a feeling of autonomy. The open organizational structure seems to allow everyone to come and to go according to their own needs and is seen as a way of being flexible and independent. Even becoming unemployed seems to be an autonomous decision as an equal partner of the Dono.

But to stay in the terminology of Berlin (1969), this is not a "positive" freedom. Although self-determination seems to be given, but is, to a specific extent, driven by social and economic circumstances. Low gold yield, lack of capital for own investments, and poor education shackle the working 
conditions of most Garimpeiros and, absurdly enough, it is perceived as freedom. This can only be explained by the hope of 1 day making the big gold discovery and then being rich. State intervention would endanger this hope and supposedly restrict freedom. This is reinforced by the fact that the state does not offer an alternative for the Garimpeiros to find out about their social situation. Therefore, this often mentioned "freedom and autonomy" could be understood as a chance for the Garimpeiros to take their fate into their own hands. But in most cases, this is an illusion. It could also be interpreted that way: As long as the state offers no real and acceptable social or economic alternative for the Garimpeiros, any state intervention will be perceived as a restriction of freedom. We decided to continue using the term "Autonomy."

The UNEP/SETAC guidelines do not include a category covering autonomy, nor do the RPSM, SHDB, or PSILCA. However, the proposed new category could be included as a subdivision of other categories. To determine whether this is the case, the aforementioned SLCA documents were reviewed to evaluate if they align with the descriptions of the social states provided in Section 3.1. All documents include categories that cover some parts of the mentioned autonomy, as shown in the Online Resource Table 3. Nevertheless, none of the categories provides a complete picture of the intangible asset of autonomy reflecting the independence from the state and its laws and from the Donos. A specific category for autonomy is currently missing in the SLCA field.

Autonomy could be investigated in SLCA by considering a different evaluation level. Proposals including autonomy as an area of protection (AoP) are discussed (Reitinger et al. 2011; Weidema 2006). Autonomy is defined as "being in control of one-self and one's resources" and is hampered by infringements on one's integrity, e.g., by forced labor, trafficking, the lack of freedom of expression (Weidema 2006). This concept could be used to assess the "Autonomy" of the Garimpeiros in the sense of "negative" freedom. However, the central point, is not covered, namely acting autonomous in their own interest and be able to fulfill, e.g., their social and economic needs. That would be the demand for a "positive" freedom.

\subsubsection{Key issue 3-excavator use}

Another aspect was identified as significant during our research: the consequences of using excavators (section "Excavators"). Environmental damage from ASGM due to the use of mercury, sediment inputs into rivers, etc. is well known and discussed in many regard (Kahhat et al. 2019; de Sousa 2010; Wotruba et al. 1998). However, the rebound effects resulting from excavators are often not the center of the discussion, but they are important. We observed the effects of excavator use. Increasing productivity with excavators has almost become standard today. The mining process can now be conducted approximately four times faster, resulting in increased environmental damage but also more gold and thus more money for making a living. Road construction is significantly facilitated with excavators, resulting in another rebound effect. Increased transportation infrastructure brings about the development of regions and again creates settlement pressure, which in turn attracts people in search of income opportunities. Although the Garimpeiros are pioneers in the settlement of rainforest, other activities, e.g., logging or farming, become more viable and lead to further environmental problems as well as new sources for livelihood.

Again, categories in the SLCA research field were reviewed. UNEP/SETAC proposed a category "technology development," but it targets the involvement of an enterprise in the development of technology (Benoit Norris et al. 2013), which cannot be applied to an informal sector such as ASGM. A case study in the SLCA research field conducted by Sierra et al. (2017) proposed a method to consider infrastructure projects from the point of view of social sustainability and included short- and long-term social improvements. As only improvements are included, no negative impacts, e.g., settlement pressure, can be assessed. Another case study focused on (novel) technologies and suggested a narrative description of qualitative indicators to reveal the potential impacts of the technology. These descriptions should be based on the literature and expert judgment and result in an evaluation regarding the concerns (no, moderate or major concerns) (van Haaster et al. 2017). Although this procedure is very time-consuming and there is a risk of subjectivity, rebound effects could be included. Until now, there have been no categories in SLCA to measure the impacts of technologies such as excavators.

\subsubsection{Key issue 4-relations and their rebound effects}

Many relations between social states and categories exist and sometimes lead to rebound effects. The qualitative analysis of the ASGM sector revealed its complexity (Section 3.1). The aspect of freedom and autonomy can serve as an example of this complexity. The absence of the state could have two consequences, of which one is the strengthening of the feeling of freedom and autonomy. This, in addition to the high bureaucratic and difficult way due to the absence of the state, the way to become legal and formal is obstructed. The illegal and informal structure itself contributes to autonomy because controls to combat illegal mining are rare, and there is no incentive to overcome the legalization process but rather obstacles due to financial reasons, high effort, and lack of support. This reinforces illegality.

The category of autonomy reflects the importance of considering relations and their effects in other social categories. The SLCA method was designed to identify and evaluate positive and negative social aspects, and it provides an inventory of social aspects and involves weighting and aggregation 
(Benoit and Mazijn 2009). In the SLCA research field, it is still challenging to identify the effects of relations and clarify where they end (Soltanpour et al. 2019).

One might think that consequential SLCA might be a solution, as the effects of the relations are consequences, but SLCA has followed an attributional approach until now. If it was consequential, it would compare an implemented life cycle to a non-implemented life cycle (Jørgensen et al. 2010), where consequences in the sense of LCA are not shown. Rebound effects, such as autonomy, would not be depicted by consequential SLCA. If ASGM did not exist, these aspects could be assessed by this approach, if there was an appropriate method.

Cause-effect models in the form of type II LCIA could be used to outline the effects of the relations, but in contrast to LCA, they are not often used in SLCA. Feschet et al. (2013), Neugebauer et al. (2014), and Bocoum et al. (2015) highlighted the need of impact pathway modeling but apply this approach only to a few pathways. Sureau et al. (2019) published an overview of 28 studies with nine different approaches for type II studies. The results of their study support the statements made here. At present, the lack of cause-effect models is a shortcoming of SLCA, as the results of relations are not recorded (Iofrida 2016).

\subsubsection{Key issue 5-relations and their rebound effects on the other parts of sustainability}

The social aspects of the ASGM sector in Brazil (Section 3.1) are complex and in many cases exceed social boundaries and interact with other parts of sustainability before they create a rebound effect. These other aspects have, in terms of sustainability, connections to the environment and the economy. This not only applies to ASGM but also appears in the formal mining sector (Di Noi et al. 2018). However, relations can be significant, especially in informal structures, and due to specific social circumstances, options for sustainable development may fail. Again, autonomy serves as an example. If we seek to save the rainforest by reducing the environmental damage from ASGM, basically two options exist. One option is to completely halt ASGM. The creation of formal alternative income opportunities to reduce poverty may be considered in this option but contradicts the intangible asset of autonomy. The chance of becoming wealthy and having selfdetermination does not exist in formal employment, where profit sharing or the payment of commissions is not common; working hours are less modifiable, and a notice period might be required. Many Garimpeiros do not want to work in the formal sector, and thus, they reject alternative income options, which make the option to reduce environmental damage not possible. Another option to reduce the burden of the environment could be the legalization and formalization of the sector, presuming that the corresponding legislation exists. However, this option is also likely to fail because it also endangers the intangible asset of autonomy. In addition, both options involve the creation of more formal structures in rural and remote areas, which both further harm the rainforest and result in a major dilemma. The construction of new (transportation) infrastructure is necessary for creating government institutions and employment options. In addition, more people might be attracted by new income opportunities, leading to settlement pressure and environmental impacts. The importance of the cultural positioning of autonomy must remain relevant if improvements are to be made in all areas of gold mining - environmental, economic, and social-in the future.

To address these challenges, a holistic view with consideration of all aspects of sustainability must be applied. This exceeds the scope of SLCA. The method was not designed to reflect these effects, nor does it have the goal of presenting a holistic view. However, there is a need to evaluate existing interdependencies with the surrounding world (Zamagni et al. 2011). SLCA, LCA, and life cycle costing (LCC), the assessment of costs along the life cycle, are part of the methodology of life cycle sustainability assessment (LCSA) (Kloepffer 2002, 2008), which might be able to reflect the ASGM sector of Brazil. There are two ways to combine the three methods. One is to separately calculate the three parts using existing methodologies. The other implies that there has been a merger of social and economic aspects into LCA and thus the development of a new method (Kloepffer 2008). Until now, the LCSA method could not overcome the challenge of assessing the connections between the different aspects of all the components of sustainability (Schaubroeck and Rugani 2017). However, as this issue is beyond the scope of SLCA, the approach of LCSA will not be pursued any further.

\section{Conclusion}

The structures of the ASGM sector in the Tapajós Region in the Brazilian rainforest are complex, and it is essential to understand the social situation, considering the overall picture. This case study investigates the social states of the ASGM sector and presents its relations (Section 3.1). The results of the qualitative analyses as well as the identified relations are illustrated in Fig. 2, which can be used to improve the understanding of the sector and to discuss options for future measures to increase sustainability. In addition, qualitative data are provided as a contribution to the research need for regional data in the SLCA research field.

The research question of whether SLCA is capable of reflecting the ASGM sector in Brazil is answered. In terms of the key issues of the sector, SLCA was limited in some 
respects. For example, it could not adequately address the nonlinear relation between the number of working hours and the amount of extracted gold or value added, which led to unstable payments (Section 3.2.1). This ratio, used as an AV in SLCA to score results, is hampered.

As shown in Section 3.2.2, SLCA cannot fully reflect all important social aspects at present. The category of autonomy was identified as key in the ASGM sector in Brazil and thus included in the analysis as an own category in addition to the categories identified in the UNEP/SETAC guidelines and the Fairmined Standard. Autonomy represents the most important intangible asset of the gold miners who hope to generate not only income but also wealth and brings about flexibility. However, this aspect can also be an obstacle. Once the informal structures of the sector are experienced, it can be difficult to go back to obeying rules. To date, no category in the SLCA research field covers this important aspect. This might have occurred because this aspect is elusive. Further investigations are required, especially in the anthropological and social sciences, to lay a foundation to integrate this intangible but highly relevant aspect.

The effectiveness of the categories assessing technologies, e.g., excavators (Section 3.2.3), depends on the underling definition, as shown in the example of the category for technology development in the UNEP/SETAC guidelines. In practice, narrative descriptions can be found, which on the one hand can show the rebound effects, even for excavators; however, the process can be time-consuming and subjective.

In regard to the assessment of relations and their effects (Section 3.2.4), SLCA does not provide answers jet and is somewhat limited. The same applies to the assessment of relations for the other components of sustainability (Section 3.2.5). The need for the creation of new categories, environment and productivity, during data analysis make it clear that all parts of sustainability must be considered so the sector can be comprehensively evaluated. The options that were suggested to counteract environmental damage and its possible consequences illustrate this importance. The results of this study indicate that interventions to formally create jobs or legalize the sector to limit the environmental impact could fail. Consequential SLCA is not designed to estimate the effects of relations. Social impact pathways are still rarely considered in the SLCA research field. The same applies for relations that go beyond social circumstances. The results show that the ecological impacts on the Amazonian rainforest resulting from gold mining cannot be solved without considering the economic and social aspects. Additionally, LCSA, of which SLCA is a part of, does not take into account these relations. This can be considered a disadvantage of the SLCA method. The real problem, however, is deeper and indicates that there is a general lack of information about the mutual influence of different aspects.
To make long-term and sustainable improvements, it is vital to understand the environmental, social, and economic structures of the situation. Complex reciprocal relationships and the effects of the impacts of the ASGM sector are central to generating such an understanding. However, until now, they have not been sufficiently described and identified. Questions concerning an appropriate acquisition and assessment are significant. Although this paper reveals some of the relations of the ASGM sector in the Tapajós Region in the Brazilian rainforest, fundamental research is needed to construct cause-effect models of miscellaneous aspects to establish the impact pathways for SLCA.

Nevertheless, SLCA provides guidance for the employment of a systematic approach. To gain experience and better understand a specific sector or situation, it is necessary to use a framework, such as that of the SLCA. It is helpful to categorize different social themes and stakeholders not only for preparatory work but also for the main body of research. Many different kinds of research have been undertaken in recent years, and much experience could be gained by considering this approach. The benefits and shortcomings of the method are known. Due to its accordance with LCA and thus the underlying life cycle perspective, SLCA is a promising method with much potential, but its further development is needed, such as integrating new categories, e.g., autonomy. In regard to the ASGM sector, it could be advantageous to conduct a general analysis of other forms of informal mining, e.g., in Indonesia or Africa.

Acknowledgments Open Access funding enabled and organized by Projekt DEAL. We would also like to thank Benjamin Fritz for being part of the research team and his valuable input. We would like to thank Dr. Sabrina Weber for her professional advice regarding qualitative research methods and the conceptualization process. In addition, we would like to thank all interviewees for providing their insights and the whole community of Garimpeiros for their support, without which this project would not have been possible. We also give much thanks to the anonymous reviewers for their valuable remarks.

Funding The Federal Ministry of Education and Research funded the NaGold project, grant number 03FH045PX5.

\section{Compliance with ethical standards}

Conflict of interest The authors declare that they have no conflict of interest.

Open Access This article is licensed under a Creative Commons Attribution 4.0 International License, which permits use, sharing, adaptation, distribution and reproduction in any medium or format, as long as you give appropriate credit to the original author(s) and the source, provide a link to the Creative Commons licence, and indicate if changes were made. The images or other third party material in this article are included in the article's Creative Commons licence, unless indicated otherwise in a credit line to the material. If material is not included in the article's Creative Commons licence and your intended use is not permitted by statutory regulation or exceeds the permitted use, you will need to obtain permission directly from the copyright holder. To view a copy of this licence, visit http://creativecommons.org/licenses/by/4.0/. 


\section{References}

ADIMB (2019) Clipping. http://adimb.org.br/ADMBLACK/clipping/ 461.pdf.

Aide TM, Clark ML, Grau HR, López-Carr D, Levy MA, Redo D, Bonilla-Moheno M, Riner G, Andrade-Núñez MJ, Muñiz M (2013) Deforestation and reforestation of Latin America and the Caribbean (2001-2010). Biotropica 45:262-271. https://doi.org/10. 1111/j.1744-7429.2012.00908.x

ANORO (2019) Anuario Anoro 2018: Mercado internacional de ouro

ARM (2019) The FAIRMINED standard for gold. https://www. fairmined.org/the-fairmined-standard/.

BBC News (2019) Amazon rainforest belongs to Brazil, says Jair Bolsonaro. https://www.bbc.com/news/world-latin-america49815731.

Benoît C, Mazijn B (2009) Guidelines for social life cycle assessment of products. http://www.unep.fr/shared/publications/pdf/ DTIx1164xPA-guidelines sLCA.pdf.

Benoît Norris C, Traverso M, Valdivia S, Vickery-Niederman G, Franze J, Azuero L, Ciroth A, Mazijn B, Aulisio D (2013) The methodological sheets for sub-categories in social life cycle assessment (SLCA). https://www.lifecycleinitiative.org/wp-content/uploads/ 2013/11/S-LCA_methodological_sheets_11.11.13.pdf.

Benoit-Norris C, Cavan DA, Norris G (2012) Identifying social impacts in product supply chains: overview and application of the social hotspot database. Sustainability 4:1946-1965. https://doi.org/10. $3390 /$ su4091946

Berlin I (1969) Two concepts of liberty. In: Berlin I (ed) Four essays on liberty. Oxford University Press, Oxford, pp 118-172

Bocoum I, Macombe C, Revéret J-P (2015) Anticipating impacts on health based on changes in income inequality caused by life cycles. Int J Life Cycle Assess 20:405-417. https://doi.org/10.1007/ s11367-014-0835-x

Bryman A, Bell E (2011) Business research methods, 3rd edn. Oxford University Press, New York

Buxton A (2013) Responding to the challenge of artisanal and small-scale mining: how can knowledge networks help? iied. U.K, London

Carter I (2016) Positive and negative liberty. https://plato.stanford.edu/ entries/liberty-positive-negative/.

Cleary D (1990) Anatomy of the Amazon gold rush. The Macmillan Press, Houndmills, Basingstoke, Hampshire and London, U.K.

Clift R (2016) Some background issues in social LCA. In: Macombe C (ed) Social LCA researcher school book: social evaluation of the life cycle, application to the agriculture and agri-food sectors. FRuiTROP Thema, Séte, pp 5-17

Cobut A, Beauregard R, Blanchet P (2013) Using life cycle thinking to analyze environmental labeling: the case of appearance wood products. Int J Life Cycle Assess 18:722-742. https://doi.org/10.1007/ s11367-012-0505-9

Corona B, Bozhilova-Kisheva KP, Olsen SI, San Miguel G (2017) Social life cycle assessment of a concentrated solar power plant in Spain: a methodological proposal. J Ind Ecol 21:1566-1577. https://doi.org/ $10.1111 /$ jiec. 12541

Ministério da Saúde (2017a) Componente Estratégico da Assistência Farmacêutica (CESAF). http://portalms.saude.gov.br/assistenciafarmaceutica/medicamentos-rename/cesaf.

Ministério da Saúde (2017b) Sistema Único de Saúde (SUS): estrutura, princípios e como funciona. http://portalms.saude.gov.br/sistemaunico-de-saude.

da Silva AR (2001) Tapajos Gold Garimpos. In: Villas-Bôas R, Beinhoff C, da Silva AR (eds) Mercury in the Tapajos Basin. Cyted-Cetem, Rio de Janeiro, pp 31-51

de Area Leão Pereira EJ, Silveira Ferreira PJ, de Santana Ribeiro LC, Sabadini Carvalho T, de Barros Pereira HB (2019) Policy in Brazil (2016-2019) threaten conservation of the Amazon rainforest.
Environ Sci Pol 100:8-12. https://doi.org/10.1016/j.envsci.2019. 06.001

de Sousa RN (2010) Planning and implementing solutions for artisanal gold mining sites, preventing environmental impacts and rehabilitating degraded areas: a Brazilian case study. The University of British Columbia, Dissertation

Di Noi C, Eisfeldt F, Ciroth A, Bizarro D (2018) Complementarity of social and environmental indicators and risks. An example of the mining industry. In: CIRAD (ed) Social LCA. People and Places for Partnership: Pre-proceedings 6th Social Life Cycle Assessment Conference 10.-12.09.2018, Pescara, pp 122-127

DIN (2009) Environmental management - life cycle assessment - principles and framework (ISO 14040:2006), ICS 13.020.10; 13.020.60. Beuth, Berlin, Germany

DIN (2011) Guidance on social responsibility (ISO 26000:2010), ICS 03.020; 03.100.01. Beuth, Berlin, Germany

DNPM (2019) SIGMINE. http://sigmine.dnpm.gov.br/webmap/.

DNPM (o.J.) Portal da Outorga: Permissão de lavra garimpeira. http:// outorga.dnpm.gov.br/SitePages/Regimes\%20PLG.aspx\#G1.

Du C, Ugaya C, Freire F, Dias LC, Clift R (2019) Enriching the results of screening social life cycle assessment using content analysis: a case study of sugarcane in Brazil. Int J Life Cycle Assess 24:781-793. https://doi.org/10.1007/s11367-018-1490-4

Eisfeldt F, Ciroth A (2017) PSILCA - a product social impact life cycle assessment database: database version 2. Documentation. https:// nexus.openlca.org/ws/files/12765. Accessed 05.02.19

Feschet P, Macombe C, Garrabé M, Loeillet D, Saez AR, Benhmad F (2013) Social impact assessment in LCA using the Preston pathway. Int J Life Cycle Assess 18:490-503. https://doi.org/10.1007/ s11367-012-0490-z

Fritz M, McQuilken J, Collins N, Weldegiorgis F (2018) Global trends in artisanal and small-scale mining (ASM): a review of key numbers and issues. https://www.iisd.org/library/global-trends-artisanal-andsmall-scale-mining-asm-review-key-numbers-and-issues.

Geenan S (2016) African artisanal mining from the inside out: access, norms and power in Congo's gold sector. Routledge studies of the extractive industries and sustainable development. Routledge, London, New York

Goedkoop MJ, Indrane D, Beer IM de (2018) Methodology for product social impact assessment

GRI (2016) GRI standards download center: social standards. https:// www.globalreporting.org/standards/gri-standards-downloadcenter/.

Heck C, Tranca J (2014) La realidad de la minería ilegal en países amazónicos. https://spda.org.pe/?wpfb_dl=414.

Hentschel T, Hruschka F, Priester M (2003) Artisanal and small-scale mining: challenges and opportunities. iied; WBCSD, London

Hilson G (2002) Small-scale mining and its socio-economic impact in developing countries. Nat Resour Forum 26:3-13. https://doi.org/ 10.1111/1477-8947.00002

Hinton JJ, Veiga MM, Veiga ATC (2003a) Clean artisanal gold mining: a utopian approach? J Clean Prod 11:99-115. https://doi.org/10.1016/ S0959-6526(02)00031-8

Hinton JJ, Veiga MM, Beinhoff C (2003b) Women and artisanal mining: gender roles and the road ahead. In: Hilson G (ed) The socioeconomic impacts of artisanal and small-scale Mining in Developing Countries, chapter 11. A.A. Balkema Publishers, Lisse

Hoadley M, Limpitlaw D (2004) The artisanal and small scale mining sector \& sustainable livelihoods. In: Mintek Small Scale Mining Conference (ed) Book of proceedings: 04.09.2004, Johannesburg, South Africa, pp 1-9

Hospido A, Milà i Canals L, McLaren S, Truninger M, Edwards-Jones G, Clift R (2009) The role of seasonality in lettuce consumption: a case study of environmental and social aspects. Int J Life Cycle Assess 14:381-391. https://doi.org/10.1007/s11367-009-0091-7 
iied, WBCSD (2002) Breaking new ground: mining. Earthscan Publications, U.K., USA, Minerals and Sustainable Development

Iofrida N (2016) Scientific paradigms in social LCA. In: Macombe C (ed) Social LCA researcher school book: social evaluation of the life cycle, application to the agriculture and agri-food sectors. FRuiTROP Thema, Séte, pp 52-65

Jørgensen A (2013) Social LCA - a way ahead? Int J Life Cycle Assess 18:296-299. https://doi.org/10.1007/s11367-012-0517-5

Jørgensen A, Le Bocq A, Nazarkina L, Hauschild M (2008) Methodologies for social life cycle assessment. Int J Life Cycle Assess 13:96-103. https://doi.org/10.1065/lca2007.11.367

Jørgensen A, Finkbeiner M, Jørgensen MS, Hauschild MZ (2010) Defining the baseline in social life cycle assessment. Int $\mathrm{J}$ Life Cycle Assess 15:376-384. https://doi.org/10.1007/s11367-0100176-3

Kahhat R, Parodi E, Larrea-Gallegos G, Mesta C, Vázquez-Rowe I (2019) Environmental impacts of the life cycle of alluvial gold mining in the Peruvian Amazon rainforest. Sci Total Environ 662:940 951. https://doi.org/10.1016/j.scitotenv.2019.01.246

Kloepffer W (2002) Life-cycle based methods for sustainable product development. In: Hertwich E (ed) Interim Report: IR-02-073, vol 8 , pp 157-159

Kloepffer W (2008) Life cycle sustainability assessment of products. Int J Life Cycle Assess 13:89-95. https://doi.org/10.1065/lca2008.02. 376

Kolen J, de Theije M, Mathis A (2013) Formalized small-scale gold mining in the Brazilian Amazon: an activity surrounded by informality. In: Cremers L, Kolen J, de Theije M (eds) Small-scale gold mining in the Amazon. Centre for Latin American Studies and Documentation, Amsterdam, pp 31-45

Kolen J, de Smet E, de Theije M (2017) "We are all Garimpeiros:" settlement and movement in communities of the Tapajós smallscale gold mining reserve. J Lat Am Caribb Anthropology 23: 169-188. https://doi.org/10.1111/jlca. 12271

Kühnen M, Hahn R (2017) Indicators in social life cycle assessment: a review of frameworks, theories, and empirical experience. J Ind Ecol 21:1547-1565. https://doi.org/10.1111/jiec.12663

Larreta ER (2002) "Gold is illusion": the Garimpeiros of Tapajos Valley in the Brazilian Amazonia. Stockholm University, Dissertation

Looted Amazon (2018) Start. https://illegalmining. amazoniasocioambiental.org/story?lang=en. Accessed 21 February 2019

Macombe C, Leskinen P, Feschet P, Antikainen R (2013) Social life cycle assessment of biodiesel production at three levels: a literature review and development needs. J Clean Prod 52:205-216. https://doi.org/ 10.1016/j.jclepro.2013.03.026

Maisonnave F (2018) Amazon at risk from Bolsonaro's grim attack on the environment. https:/www.theguardian.com/environment/2018/ oct/09/brazils-bolsonaro-would-unleash-a-war-on-the-environment.

Mancini L, Sala S (2018) Social impact assessment in the mining sector: review and comparison of indicators frameworks. Resour Policy 57: 98-111. https://doi.org/10.1016/j.resourpol.2018.02.002

Martínez-Blanco J, Lehmann A, Muñoz P, Antón A, Traverso M, Rieradevall J, Finkbeiner M (2014) Application challenges for the social life cycle assessment of fertilizers within life cycle sustainability assessment. J Clean Prod 69:34-48. https://doi.org/10.1016/j. jclepro.2014.01.044

Massaro L, de Theije M (2018) Understanding small-scale gold mining practices: an anthropological study on technological innovation in the Vale do Rio Peixoto (Mato Grosso, Brazil). J Clean Prod 204: 618-635. https://doi.org/10.1016/j.jclepro.2018.08.153

Mathis A (2003) Report in reference to São Chico and Crepurizinho mining sites. http://www.artisanalmining.org/Repository/02/The GMP_Files/processed\%20files\%20-\%20iwlearn.net/Reports $\% 20 \%$ 28 by $\overline{\%} 20$ country $\% 29 /$ Brazil/report-in-reference-to-sao-chico-andcrepurizinho-mining-sites.pdf.
Mathis A (2012) Artisanal and small-scale gold mining in the North of Brazil: (Amapá and the North of Pará). http://d2ouvy59p0dg6k. cloudfront.net/downloads/2011_artisinal_and_small_scale_gold mining_in_the_north_of_brazil_1.pdf.

Mayring P (2014) Qualitative content analysis: theoretical foundation, basic procedures and software solution, Klagenfurt

Muthu SS (ed) (2015) Social life cycle assessment: an insight. Environmental Footprints and Eco-design of Products and Processes. Springer Singapore, Singapore, Republic Singapore

Neugebauer S, Traverso M, Scheumann R, Chang Y-J, Wolf K, Finkbeiner M (2014) Impact pathways to address social well-being and social justice in SLCA - fair wage and level of education. Sustainability 6:4839-4857. https://doi.org/10.3390/su6084839

Neugebauer S, Traverso M, Blengini GA, Mathieux F, Peiter CC (2018) Social life cycle assessment of niobium mining in Brazil in a circular economy context. In: CIRAD (ed) Social LCA. People and Places for Partnership: Pre-proceedings 6th Social Life Cycle Assessment Conference 10.-12.09.2018, Pescara, Italy, pp 194-196

Owusu O, Bansah KJ, Mensah AK (2019) "Small in size, but big in impact": socio-environmental reforms for sustainable artisanal and small-scale mining. J Sustain Min 18:38-44. https://doi.org/10. 1016/j.jsm.2019.02.001

Parent J, Cucuzzella C, Revéret J-P (2010) Impact assessment in SLCA: sorting the sLCIA methods according to their outcomes. Int J Life Cycle Assess 15:164-171. https://doi.org/10.1007/s11367-0090146-9

Petti L, Sanchez Ramirez PK, Traverso M, Ugaya CML (2018) An Italian tomato "Cuore di Bue" case study: challenges and benefits using subcategory assessment method for social life cycle assessment. Int J Life Cycle Assess 23:569-580. https://doi.org/10.1007/s11367016-1175-9

Phillips D (2019) Amazon rainforest 'close to irreversible tipping point'. The Guardian 23(10):2019

Presidência da República, Casa Civil (1967) DECRETO-LEI N²27: DE 28 DE FEVEREIRO DE 1967

Presidência da República, Casa Civil (1989) LEI N 7.805: DE 18 DE JULHO DE 1989

Presidência da República, Casa Civil (2008) LEI No 11.685: DE 2 DE JUNHO DE 2008

Priester M, Hentschel T (1992) Small-scale gold-mining: processing techniques in developing countries. Vieweg, Braunschweig

Reitinger C, Dumke M, Barosevcic M, Hillerbrand R (2011) A conceptual framework for impact assessment within SLCA. Int J Life Cycle Assess 16:380-388. https://doi.org/10.1007/s11367-011-0265-y

Schaubroeck T, Rugani B (2017) A revision of what life cycle sustainability assessment should entail: towards modeling the net impact on human well-being. J Ind Ecol 21:1464-1477. https://doi.org/10. $1111 /$ jiec. 12653

Schmidt M, Peregovich B (2015) Artisanal Gold Mining im Amazonas Regenwald: Ein Fallbeispiel für Zielkonflikte der Nachhaltigkeit. Horizonte; April 2015:24-30

Seccatore J, Veiga M, Origliasso C, Marin T, de Tomi G (2014) An estimation of the artisanal small-scale production of gold in the world. Sci Total Environ 496:662-667. https://doi.org/10.1016/j. scitotenv.2014.05.003

Siebert A, Bezama A, O'Keeffe S, Thrän D (2016) Social life cycle assessment: in pursuit of a framework for assessing wood-based products from bioeconomy regions in Germany. Int J Life Cycle Assess 23:651-662. https://doi.org/10.1007/s11367-016-1066-0

Sierra LA, Pellicer E, Yepes V (2017) Method for estimating the social sustainability of infrastructure projects. Environ Impact Assess Rev 65:41-53. https://doi.org/10.1016/j.eiar.2017.02.004

Social Accountability International (2014) SA:8000 http://www.sa-intl. org/_data/global/files/SA8000Standard2014(3).pdf. 
Soltanpour Y, Peri I, Temri L (2019) Area of protection in S-LCA: human well-being or societal quality. Int J Life Cycle Assess 108:20732087. https://doi.org/10.1007/s11367-019-01620-y

Sousa RN, Veiga MM (2007) Implementing programs to improve gold recovery and reduce environmental impacts by artisanal small gold mining in Brazil. http://www.trcr.bc.ca/wp-content/uploads/2011/ 11/2008-book-award-paper_Sousa-Viega.pdf.

Sousa RN, Veiga MM (2009) Using performance indicators to evaluate an environmental education program in artisanal gold mining communities in the Brazilian Amazon. AMBIO: A Journal of the Human Environment 38:40-46. https://doi.org/10.1579/0044-7447-38.1.40

Spierling S, Knüpffer E, Behnsen H, Mudersbach M, Krieg H, Springer S, Albrecht S, Herrmann C, Endres H-J (2018) Bio-based plastics A review of environmental, social and economic impact assessments. J Clean Prod 185:476-491. https://doi.org/10.1016/j.jclepro. 2018.03.014

Sureau S, Neugebauer S, Achten WMJ (2019) Different paths in social life cycle impact assessment (S-LCIA) - a classification of type II impact pathway approaches. Int J Life Cycle Assess 20:161-393. https://doi.org/10.1007/s11367-019-01693-9

Teah HY, Onuki M (2017) Support phosphorus recycling policy with social life cycle assessment: a case of Japan. Sustainability 9:1223. https://doi.org/10.3390/su9071223

Transparency International (2019) Corruption Perceptions Index:2018 https://www.transparency.org/cpi2018\#downloads.

Traverso M, Finkbeiner M, Jørgensen A, Schneider L (2012) Life cycle sustainability dashboard. J Ind Ecol 16:680-688. https://doi.org/10. 1111/j.1530-9290.2012.00497.x

Valdivia SM, Ugaya CML (2011) Life cycle inventories of gold artisanal and small-scale mining activities in Peru. J Ind Ecol 15:922-936. https://doi.org/10.1111/j.1530-9290.2011.00379.x

van Haaster B, Ciroth A, Fontes J, Wood R, Ramirez A (2017) Development of a methodological framework for social life-cycle assessment of novel technologies. Int J Life Cycle Assess 22:423440. https://doi.org/10.1007/s11367-016-1162-1

Veiga MM (2013) Small gold mining can be beautiful: problems and possible solutions. The University of British, Columbia
Veiga MM, Metcalf SM, Baker R, Klein B, Davis G, Bamber A, Siegel S, Singo P (2006) Manual for training artisanal and small-scale gold miners: project EG/GLO/01/G34

Villas-Bôas R (2003) Information on project sites in Brazil. http://archive. iwlearn.net/globalmercuryproject.org/countries/brazil/docs/brazil\% 20 project $\% 20$ site\%20info.pdf.

Weidema BP (2006) The integration of economic and social aspects in life cycle impact assessment. Int J Life Cycle Assess 11:89-96. https://doi.org/10.1065/lca2006.04.016

Weidema BP, Ekvall T (2009) Chapter for CALCAS deliverable D18, 2009 "Guidelines for applications of deepened and broadened LCA": consequential LCA. https://lca-net.com > files > consequential_LCA_CALCAS_final.

Wotruba H, Hentschel T, Livan K, Hruschka F, Priester M (1998) Environmental management in small-scale mining. CID - Plural publishers, the Peace, Bolivia

WSI Institute of Economic and Social Research (2019) WSI Minimum Wage Database. Brazil. https://www.boeckler.de/pdf/ta_brazil mwdb.pdf

Yanow D, Ybema S, van Hulst M (2013) Practicing organizational ethnography. In: Symon G, Cassell C (eds) Qualitative organizational research: core methods and current challenges. Sage, London, U.K., pp 331-350

Zamagni A (2018) SCORELCA project: investigation of status and needs for social LCA. https://www.researchgate.net/publication/ 329451258_SCORELCA_project_investigation_of_status_and needs_for_social_LCA.

Zamagni A, Amerighi O, Buttol P (2011) Strengths or bias in social LCA? Int J Life Cycle Assess 16:596-598. https://doi.org/10. 1007/s11367-011-0309-3

Zamani B (2016) The challenges of fast fashion: environmental and social LCA of Swedith clothing consumption. Chalmers University of Technology, Dissertation

Zerazion E, Lehmann A, Finkbeiner, Matthias, Ferrari, Anna Maria (2018) Setting the SOLCA concept framework to the artisanal and small-scale mining sector: a case study. In: CIRAD (ed) Social LCA. People and Places for Partnership: Pre-proceedings 6th Social Life Cycle Assessment Conference 10.-12.09.2018, Pescara, Italy, pp 216-220 